\title{
Helicobacter pylori infection and growth delay in older children
}

Francesco Perri, Maria Pastore, Gioacchino Leandro, Rocco Clemente, Yvo Ghoos, Marc Peeters, Vito Annese, Michele Quitadamo, Anna Latiano, Paul Rutgeerts, Angelo Andriulli

\begin{abstract}
It is thought that Helicobacter pylori infection may influence growth rate in children. The aim of this study was to evaluate the prevalence of $H$ pylori infection in healthy Italian children, and to look for differences in height between infected and non-infected subjects. Two hundred and sixteen children, aged 3 to 14 years, were tested for $H$ pylori infection by ${ }^{13} \mathrm{C}$-urea breath test. Centile values for height were calculated. Composite indices for socioeconomic class and household crowding were also determined. Forty nine of 216 children $(22.7 \%)$ were $H$ pylori positive. The prevalence of infection increased with age. Eight of $49 \mathrm{H}$ pylori positive children $(16.3 \%)$ were below the 25th centile for height, compared with 13 of $167 \mathrm{H}$ pylori negative children $(7.8 \%)$. This difference became significant in children aged 8.5 to 14 years; in this group (n $=127$ ), eight of 31 infected children $(25.8 \%)$ were below the 25 th centile for height, compared with eight of 96 noninfected children (8.3\%). A significant correlation was found between socioeconomic conditions, household crowding, and $H$ pylori status. By using stepwise logistic regression, only the centile value for height was significantly related to $H$ pylori status in older children. Thus $H$ pylori infection was associated with growth delay in older children, poor socioeconomic conditions, and household overcrowding. This finding is consistent with the hypothesis that $H$ pylori infection is one of the environmental factors capable of affecting growth.

(Arch Dis Child 1997;77:46-49)
\end{abstract}

Keywords: growth; height; Helicobacter pylori; urea breath test

Helicobacter pylori infection is a common chronic infection ${ }^{1}$ associated with chronic gastritis, ${ }^{2}$ gastric and duodenal ulcer, ${ }^{3}$ and probably gastric cancer. ${ }^{4}$ Once acquired, the infection lasts several decades, with a very low spontaneous eradication rate. $H$ pylori is generally acquired early in life ${ }^{5}$ and socioeconomic conditions are regarded as the most important risk factors for acquisition of the infection. ${ }^{6}$

Like other chronic diseases, $H$ pylori infection might impair growth. Three studies have already shown a difference in height between infected and non-infected children. One study in the developing world detected $H$ pylori infection mostly in poor children, and short stature appeared to be related to a low nutrient intake rather than to $H$ pylori itself. ${ }^{7}$ A subsequent study from Europe showed that over half of children investigated for short stature were infected with $H$ pylori. ${ }^{8}$ However, no controls were considered. A Scottish study found that $H$ pylori infection was associated with growth delay only in girls around puberty. ${ }^{9}$

Common to all these studies, however, is a lack of information about the socioeconomic conditions which may affect height, as shown by the positive correlation between increasing height observed over past centuries and better living conditions in industrially developed societies. ${ }^{10}$ The exact mechanism of this association has not been completely elucidated but the gradual disappearance of chronic infections is a plausible explanation. ${ }^{11}$

The aim of our study was to look for differences in stature between infected and noninfected children, taking into account socioeconomic conditions and household crowding. The ${ }^{13} \mathrm{C}$-urea breath test ${ }^{12}$ was used for $H$ pylori detection since it is easy to perform, non-invasive, and accurate in determining the presence of infection.

\section{Methods}

STUDY POPULATION

Between 1994 and 1995, a cross sectional study was carried out on all schoolchildren aged 3 to 14 years living in San Giovanni Rotondo (Italy). Subjects for the study were selected from the school register, after random stratified sampling with proportional allocation by age and sex. Before starting the study, a letter explaining its purpose was sent to all enrolees' parents.

\section{QUESTIONNAIRE}

The letter contained a questionnaire which was designed to obtain demographic information on the parents, such as their date and place of birth, race, educational level, type of occupation, type of house, number of rooms, and number of people who lived in the house. Parents were also asked if their children had suffered from any relevant disease in the past or had been given antibiotics in the last month. A consent form was signed by all parents before participation in the study. The study protocol was approved by the ethics committee of 'Casa Sollievo della Sofferenza' Hospital in San Giovanni Rotondo. 
Table 1 Socioeconomic class was obtained by scoring the educational and occupational levels of both parents. A score of 0 was given to parents with the lowest level of education and occupation. A score of 4 was given to parents with the highest level. Four socioeconomic classes (from I to IV) were obtained on the basis of the scores of parents' educational and occupational levels

\begin{tabular}{llll}
\hline Education & Score & Occupation & Score \\
\hline No education & 0 & No occupation & 0 \\
Elementary school & 1 & Workman & 1 \\
Junior school & 2 & Blue collar worker & 2 \\
High school & 3 & White collar worker & 3 \\
University & 4 & Professional & 4 \\
Educational and occupational scores of parents & Socioeconomic class & \\
\hline $0-4$ & & I & \\
$5-8$ & & II & \\
$9-12$ & II & \\
$13-16$ & IV & \\
\hline
\end{tabular}

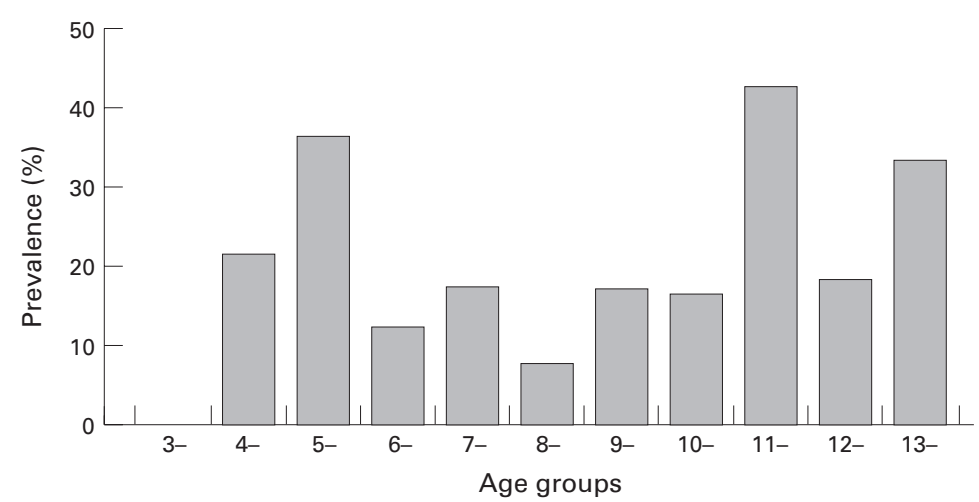

Figure 1 Prevalence of $\mathrm{H}$ pylori infection in Italian children.

\section{METHODS OF ANALYSIS}

We constructed a composite index for socioeconomic class based on parents' occupation and education by applying the Hollingshead index. ${ }^{13}$ Five occupational categories and five educational levels were used for each parent (table 1). A score of 0 was given to the lowest level of education and occupation and a score of 4 was given to the highest. Four socioeconomic classes (from I to IV) were obtained on the basis of the sum of parents' educational and occupational scores (table 1).

A crowding index was obtained by dividing the number of people living in the household by the number of rooms. Two classes were identified: class I had a crowding index less than 1 and class II greater than 1 .

\section{UREA BREATH TEST}

Children were tested for $H$ pylori infection by a ${ }^{13} \mathrm{C}$-urea breath test, ${ }^{12}$ which was performed after an overnight fast. Each subject received the test meal consisting of $210 \mathrm{ml}$ of milk and $75 \mathrm{mg}$ of $\left[{ }^{13} \mathrm{C}\right]$-urea $\left({ }^{13} \mathrm{C}, 99 \%\right.$; Isotec, Ohio, USA). Breath samples were taken before and every 15 minutes after ingestion of the test meal for one hour. ${ }^{13} \mathrm{C}$ enrichment in breath was determined by isotope ratio mass spectrometry (ANCA-NT, Europa Scientific, Crewe). The $\delta$ values were expressed in relation to the PDB international standard, after correction for the oxygen isotope effect. ${ }^{14}$ Analytical data were expressed as percentages of ${ }^{13} \mathrm{CO}_{2}$ recovery of the administered dose per hour. The percentage of the cumulative dose of ${ }^{13} \mathrm{CO}_{2}$ at one hour (CD60) was calculated by trapezoidal rule. $\mathrm{CO}_{2}$ production was assumed to be $300 \mathrm{mmol} / \mathrm{m}^{2}$ of body surface area per hour. ${ }^{15}$ Body surface area was calculated using the weight-height formula of Haycock et al. ${ }^{16}$ The ${ }^{13} \mathrm{C}$-urea breath test was considered positive if the CD60 was $\geqslant 1.2 \%$ (by using this cut off, sensitivity and specificity of the urea breath test are respectively $95 \%$ and $100 \%) .{ }^{17}$

HEIGHT AND WEIGHT MEASUREMENT

The standing height $(\mathrm{cm})$ and the weight $(\mathrm{kg})$ of each subject were recorded by the same experienced paediatrician (MP) who was unaware of the $H$ pylori status of the children. Centile values of height and weight were calculated by using standard Italian height and weight charts. For statistical purposes, children were sorted into two groups, the 25 th centile values for height or weight being the threshold values.

OTHER MEASUREMENTS

All children who were below the 25 th centile value for height were evaluated for coeliac disease. IgG and IgA class antigliadin (AGA) and antiendomysial antibodies (EmA) were assayed by means of a commercial enzyme linked immunosorbent assay (ELISA) (Eurospital, Trieste, Italy).

STATISTICAL ANALYSES

Univariate statistical analysis was made by Student's $t$ test and the $\chi^{2}$ test. ${ }^{18}$ A stepwise logistic regression analysis was carried out to evaluate the independent influence of each variable (centile value of height and weight, sex, socioeconomic class, and crowding class) on $H$ pylori status. ${ }^{18}$

ANALYSIS OF NON-RESPONDERS

All non-responders were interviewed by telephone and reasons for non-response were recorded (classified as not willing to participate or uncertain about participating in the study). Information on demographic data and children's height was obtained from the parents.

\section{Results}

The sample population consisted of 308 children. The response rate was $70 \%$ so the final sample studied was 216 subjects. We found no significant difference between responders and non-responders so far as socioeconomic or crowding indices and children's height or weight were concerned.

Forty nine out of 216 children (22.7\%) were infected with $H$ pylori. No difference in sex between $H$ pylori positive and negative subjects was found. The prevalence rate of infection increased with age, from $0 \%$ in the youngest group (3-4 years) to $33 \%$ in the oldest group (13-14 years). Figure 1 shows the prevalence rate in the different age groups: a bimodal distribution is evident with two peaks of prevalence at 5 and 11 years.

Children were divided according to their centile value for height (fig 2 ). We found that $16.3 \%$ (8/49) $H$ pylori positive children were below the 25th centile for height $(\mathrm{p}=0.09)$, compared with $7.8 \%$ of $H$ pylori negative children (13/167). Although the trend was not sig- 
$<25$ th centile $\square>25$ th centile

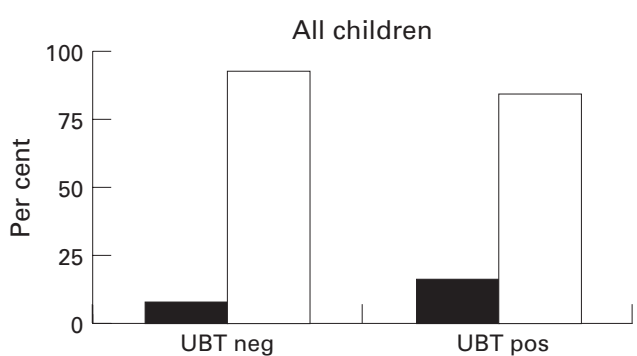

Figure $2 \mathrm{H}$ pylori infected and non-infected children divided by height centiles (UBT neg/pos $={ }^{13} \mathrm{C}$-urea breath test negative/positive).

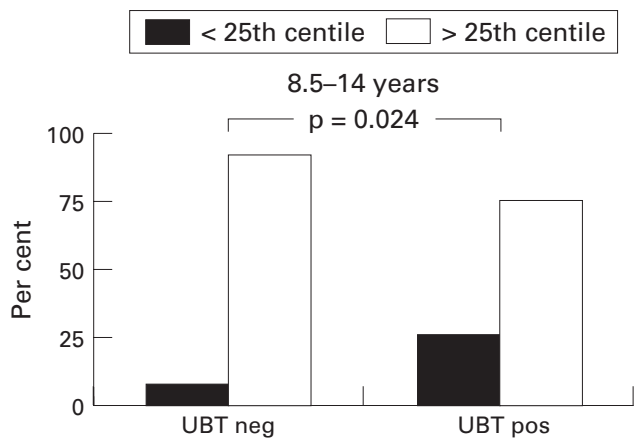

Figure $3 \mathrm{H}$ pylori infected and non-infected children aged $8.5-14$ years divided by height centiles. (UBT neg/pos = ${ }^{13} \mathrm{C}$-urea breath test negative/positive).

nificant, $H$ pylori infected children tended to have a lower centile value for height than noninfected children. This trend became significant when only the older children were considered. Thus in children aged 8.5 to 14 years, $25.8 \%$ of $H$ pylori positive children (8/31) were below the 25 th centile for height $(\mathrm{p}=0.024)$ compared with $8.3 \%$ of $H$ pylori negative children (8/96) (fig 3). Neither the affected nor the unaffected children who were below the 25 th centile for height were found to be positive on antigliadin and antiendomysial antibody testing. Centile values for weight and body surface area were also considered, but we found no difference between infected and non-infected children (data not shown).

When $H$ pylori status was taken as the dependent variable, stepwise logistic regression analysis showed that the only variables which entered into the model were the socioeconomic class $(\mathrm{F}=10.87 ; \mathrm{p}=0.001)$ and the centile value for height $(\mathrm{F}=2.42 ; \mathrm{p}=0.12, \mathrm{NS})$. When the older children were considered independently, the only variables which entered into the model were the centile value for height $(\mathrm{F}=6.74 ; \mathrm{p}=0.011)$ and socioeconomic class $(\mathrm{F}=3.24 ; \mathrm{p}=0.07, \mathrm{NS})$.

\section{Discussion}

The overall prevalence of $H$ pylori infection in children living in south Italy is about $23 \%$. This figure is higher than the rate reported in children living in north Italy $^{19}$ and in Europe, ${ }^{20-22}$ but lower than in Africa ${ }^{2123}$ or India. ${ }^{24}$ Our results may reflect the situation in a city with acceptable living conditions, where most people have a job and live in their own houses; however, the social environment is basically rural, the cultural background not generally high, and poor sanitation is still common. As several other studies have shown, poor socioeconomic conditions associated with overcrowding and inadequate hygiene at home are important risk factors for $H$ pylori infection. ${ }^{21}{ }^{25}$ Indeed, in our study a significant correlation was found between socioeconomic conditions, household crowding, and $H$ pylori status, confirming the previously reported data. Since environmental factors are important in determining $H$ pylori acquisition, the prevalence rate is expected to increase with age. In our study population, we found no cases of infection in children aged 3 to 4 years, and $33 \%$ prevalence in those aged 13 to 14 years.

The effect of $H$ pylori on growth was studied by dividing the children into two different groups according to age. Our hypothesis was that if $H$ pylori infection were able to influence growth, this would be more evident in older children with a long lasting infection than in younger children with a recently acquired infection. Since it is mainly affected by age, height by itself cannot be used to test the hypothesis. By considering the centile value for height, a significant difference in height was found between infected and uninfected children in those older than 8.5 years. In this age group, when the $H$ pylori status was taken as the dependent variable in a logistic regression analysis, only the centile value for height was able to enter into the model. This finding is consistent with the hypothesis that once acquired in early childhood $H$ pylori infection takes several years before it starts to affect growth.

The mechanisms by which $H$ pylori infection might lead to short stature are largely unknown. One possible explanation is that it could cause dyspeptic symptoms, but this does not seem to be the case in the present study since all children were healthy and had not suffered from any relevant illnesses in the past. Alternatively, the infection could result in a low energy intake and malnutrition. This is also unlikely since no effect on growth was observed in the younger subjects and all the children were well nourished. Moreover, no difference in the centile value for weight or in body surface area was detected among infected and non-infected children. A third explanation is based on the assumption that long standing infection induces low grade chronic gastric inflammation and the release of cytokines like interleukin- $8^{26}$ which would in turn affect growth. ${ }^{27}$ However, there are no data on the circulating levels of these cytokines in infected children, nor is it very likely that these substances influence distant organs. Finally, $H$ pylori may be associated with a poor socioeconomic background, malnutrition, and exposure to other chronic diseases which could affect growth independently. In our study, socioeconomic status was related with the presence of $H$ pylori infection. However, none of the children with short stature had suffered from relevant chronic infectious diseases in the past nor did any have overt signs of malnutri- 
tion. Moreover, logistic regression analysis showed that height was not influenced by socioeconomic status or crowding class. Consequently, even if poor socioeconomic conditions or household overcrowding could determine early acquisition of the infection, $H$ pylori is associated with short stature through mechanisms that are independent of socioeconomic status or crowding class.

Our findings that $H$ pylor $i$ infection acquired in childhood is associated with short stature and poor socioeconomic conditions have at least two implications. First, $H$ pylori infection could be one of the environmental causes of growth delay. The decline in incidence of $H$ pylori infection related to general improvements in socioeconomic conditions could be responsible in part for the trend toward increased height growth observed during the last century in developed countries. Second, therapeutic intervention against $H$ pylori infection in children could be recommended not only to prevent ulcer disease or gastric cancer but also to avoid interference with growth. In this respect, we recommend a well designed study in which growth velocity rather than height by itself is evaluated, either before and after $H$ pylori eradication.

We conclude that $H$ pylori infection in Italy is common in childhood, with a prevalence rate approaching $33 \%$ by the age of 14 . Early acquisition of $H$ pylori infection seems to depend on poor socioeconomic conditions and household overcrowding and is related to short stature. Mechanisms by which $H$ pylori infection might influence growth are unknown, although a direct effect cannot be excluded. Further investigations are needed to discover whether therapeutic intervention in otherwise healthy $H$ pylori infected children would avoid restricted or delayed growth.

Supported by European Concerted Action BIOMED, BMH1CT93-1239. We thank B Geypens, V Contangelo, E Squarcella, M G Latiano, A Luypaert, L Swinnen, S Rutten, N Gorris, and was carried out by $\mathrm{G}$ Leandro MD, biostatistician.

1 Megraud F. Epidemiology of Helicobacter pylori infection: where are we in 1995? Eur $\mathcal{F}$ Gastroenterol Hepatol 1995;7:292-5.

2 Warren JR, Marshall BJ. Unidentified curved bacilli on gastric epithelium in active chronic gastritis. Lancet 1983;i: 1273-5.

3 Marshall BJ, Warren JR. Unidentified curved bacilli in the stomach of patients with gastritis and peptic ulceration. stomach of patients wit $1984 ; \mathbf{i}: 1311-4$.

4 The Eurogast study group. An international association between Helicobacter pylori infection and gastric cancer Lancet 1993;341:1359-62.
5 Banatvala N, Mayo K, Megraud F, et al. The cohort effect and Helicobacter pylori. F Infect Dis 1993;168:219-21.

6 Fiedorek SC, Malaty HM, Evans DL, et al. Factors influencing the epidemiology of Helicobacter pylori in children. Pediatrics 1991;88:578-82.

7 Klein PD, Graham DY, Gaillour A, Opekun AR, Smith EO. Water source as risk factor for Helicobacter pylori infection in Peruvian children. Gastrointestinal Physiology Working Group. Lancet 1991;337:1503-6.

8 Raymond J, Bergert M, Benhamou H, Mensah K, Dupont C. A 2 -year study of Helicobacter pylori in children. $\mathcal{F}$ Clin Microbiol 1994;32:461-3.

9 Patel P, Mendall MA, Khulusi S, Northfield TC, Strachan DP. Helicobacter pylori infection in childhood: risk factors and effect on growth. BM7 1994;309:1119-23.

10 Susanne $\mathrm{CH}$. Socio-economic differences in growth patterns. In: Johnston $\mathrm{FE}$, Roche $\mathrm{AF}$, Susanne $\mathrm{CH}$, eds. Human physical growth and maturation. Methodology and factors. New York: Plenum Press, 1980:329-38.

11 Roche AF. Secular trends in stature, weight and maturation. In: Monographs of the Society for Research in Child Development. Secular trends in growth, maturation and development of children. New York, 1979: serial No 179.

12 Perri F, Ghoos Y, Hiele M, Andriulli A, Rutgeerts P. The urea breath test: a non-invasive clinical tool for detecting Helicobacter pylori infection. Ital f Gastroenterol 1995;27: 55-63.

13 Hollingshead $\mathrm{AB}$ ed. Two factor index of social position. New Haven, CT: Yale University Press, 1957.

14 Mook WG, Grootes PM. The measuring procedure and corrections for the high-precision mass-spectrometric analysis of isotopic abundance ratios, especially referring to carbon, oxygen and nitrogen. Int $\mathcal{F}$ Mass Spectrom Ionic Phys 1973;12:273-98.

15 Shreeve Ww, Cerasi E, Luft R. Metabolism of $\left[2-{ }^{14} \mathrm{C}\right]$ pyruvate in normal, acromegalic and HGH-treated human subjects. Acta Endocrinol 1970;65:155-69.

16 Haycock GB, Chir B, Schwartz GJ, Wisotsky DH. Geometric method for measuring body surface area: a heightweight formula validated in infants, children and adults. $\mathcal{F}$ Pediatr 1978;93:62-6.

17 Perri F. The urea breath test: methodological problems and application in epidemiological studies. Leuven: University of Leuven, 1996:27-40 [thesis].

18 BMDP, Biomedical Data Processing. San Francisco: University of California Press, 1994

19 De Giacomo C, Lisato L, Negrini R, Licardi G, Maggiore G. Serum immune response to Helicobacter pylori in children: epidemiological and clinical applications. $f$ Pediatr 1991;119:205-10.

20 Blecker U, Hauser B, Lanciers S. The prevalence of Helicobacter pylori-positive serology in asymptomatic children. $\mathcal{F}$ Pediatr Gastroenterol Nutr 1993;16:252-6.

21 Megraud F, Brassens Rabbe MP, Denis F, Belbouri A, Hoa DQ. Seroepidemiology of Campylobacter pylori infection in various populations. $\mathcal{F}$ Clin Microbiol 1989;27:1870-3.

22 Jones DM, Eldridge J, Fox AJ. Antibody to the gastric Campylobacter-like organism ('Campylobacter pyloridis'): clinical correlations and distribution in the normal population. 7 Med Microbiol 1986;22:57-62.

23 Holcombe C, Omotara BA, Eldridge J. H pylori, the most common bacterial infection in Africa: a random serological study. Am F Gastroenterol 1992;87:28-30.

24 Graham DY, Adam E, Reddy GT. Seroepidemology of Helicobacter pylori infection in India. Comparison of developing and developed countries. Dig Dis Sci 1991;36:1084-8.

25 Mendall MA, Goggin PM, Molineaux N, Levy J, Toosy T, Strachan D. Childhood living conditions and Helicobacter pylori seropositivity in adult life. Lancet 1992;339:896-7.

26 Crabtree JE, Peichl P, Wyatt JI, Stachl U, Lindley IJ. Gastric interleukin-8 and IgA IL-8 autoantibodies in Helicobacter pylori infection. Scand f Immunol 1993;37:65-70.

27 Murch SH, Lamkin VA, Savage MO, Walker-Smith JA, MacDonald TT. Serum concentrations of tumour necrosis factor alpha in childhood chronic inflammatory disease. Gut 1991;32:913-7. 